\title{
Tangence
}

Victor-Laurent Tremblay, Au commencement était le mythe. Tangence Introduction à une mythanalyse globale avec application à la culture traditionnelle québécoise à partir de quelques textes romanesques représentatifs, Ottawa, Les Presses de l'Université d'Ottawa, 1991.

\section{Jean Morency}

Numéro 38, décembre 1992

Fiction policière et roman actuel

URI : https://id.erudit.org/iderudit/025745ar

DOI : https://doi.org/10.7202/025745ar

Aller au sommaire du numéro

Éditeur(s)

Tangence

ISSN

1189-4563 (imprimé)

1710-0305 (numérique)

Découvrir la revue

Citer ce compte rendu

Morency, J. (1992). Compte rendu de [Victor-Laurent Tremblay, $A u$ commencement était le mythe. Introduction à une mythanalyse globale avec application à la culture traditionnelle québécoise à partir de quelques textes romanesques représentatifs, Ottawa, Les Presses de l'Université d'Ottawa, 1991.]

Tangence, (38), 121-123. https://doi.org/10.7202/025745ar d'utilisation que vous pouvez consulter en ligne. 


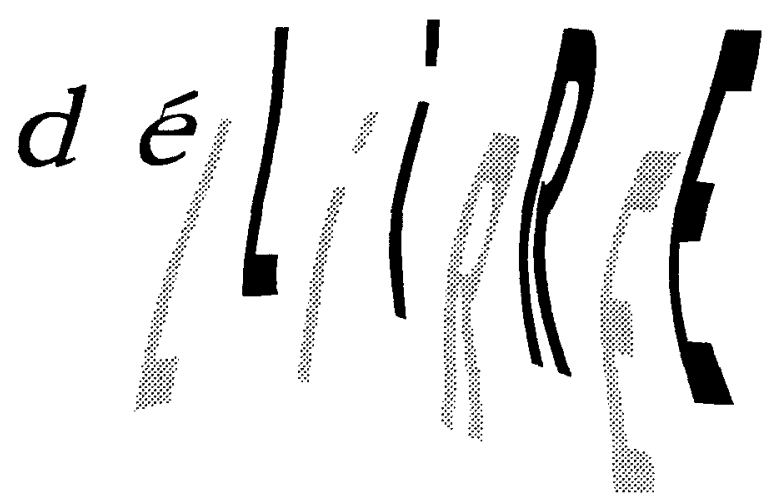

Victor-Laurent Tremblay, Au commencement était le mythe. Introduction à une mythanalyse globale avec application a la culture traditionnelle québécoise à partir de quelques textes romanesques représentatifs, Ottawa, Les Presses de l'Université d'Ottawa, 1991.

Les plus récentes études qui ont été consacrées à la littérature québécoise du $\mathrm{XIX}^{\mathrm{c}}$ siècle (je pense en particulier aux ouvrages de Réjean Beaudoin et de Robert Major, Naissance d'une littérature et Jean Rivard ou l'art de réussir) ont contribué à remettre en question la vision communément admise de cette période de notre histoire littéraire, ainsi qu'à réhabiliter certaines des cuvres, longtemps dénigrées ou ignorées dans le milieu intellectuel, qui la jalonnent. L'important travail de Victor-Laurent Tremblay se situe dans ce mouvement de redécouverte et de relecture du passé littéraire québécois, du moins en ce qui concerne la méthodologie adoptée: si Robert Major, par exemple, bouscule certaines idées reçues lorsqu'il met en lumière l'américanité profonde du roman de Gérin-Lajoie, tranchant ainsi sur l'historiographie traditionnelle, davantage préoccupée par les questions entourant la contrainte exercée par le clergé et l'idéologie ultramontaine sur l'émergence de la littérature, VictorLaurent Tremblay cherche plutôt à dévoiler les mécanismes imaginaires sur lesquels se fonde, dans son apparition et son évolution, le roman québécois, sans toutefois remettre directement en question l'influence dominante du discours ultramontain.

Bien au contraire, c'est ce discours qui, en s'appuyant sur des structures mythiques relativement stables qui remontent à la tradition orale, englobe l'essentiel de la production littéraire de la 
période étudiée. L'auteur retrace donc l'évolution historique de ces structures mythiques en appliquant à ses matériaux littéraires, assez audacieusement, il faut le préciser, les théories de Gilbert Durand, de René Girard et de Mikhaïl Bakhtine, théories qu'il parvient, à l'aide de tableaux complexes, à conjuguer. L'exercice - périlleux - apparaît pourtant convaincant: à la juxpaposition des deux régimes de l'imaginaire de Durand, le Régime Diurne et le Régime Nocturne, Tremblay fait correspondre le double processus défini par Girard (la différenciation culturelle et l'indifférenciation instinctuelle), ainsi que le monolinguisme et le plurilinguisme bakhtiniens. Au cœur du conflit structurel que Tremblay met à jour, on retrouve la dialectique essentielle des doubles qui incarne, selon le modèle girardien du désir mimétique et du sacrifice victimaire, l'affrontement de l'ordre culturel et de la nature instinctuelle.

Depuis la tradition orale jusqu'au roman du terroir, le «mythoromanesque "québécois se fonde sur cette lutte entre les doubles qui débouche infailliblement sur le sacrifice, ce dernier venant conforter l'ordre social et commautaire. "Mytho-romanesque " en effet, puisque le roman québécois traditionnel, caractérisé par l'unilinguisme et l'emprise du discours "rhétorico-judiciaire", patriarcal et ultramontain, ne saurait prétendre à autre chose qu'à proclamer la survie et la cohésion du clan, de la tribu, de la communauté. La mythanalyse à laquelle se livre Tremblay dévoile, à travers les œuvres étudiées - La chasse-galerie, L'influence d'un livre, Les anciens Canadiens, Angéline de Montbrun et Un bomme et son péché -, l'action déterminante de ce mythe ne racontant jamais, finalement, qu'un seul récit, celui de la transgressionpunition-conservation. Dans le recueil d'Honoré Beaugrand, par exemple, les légendes de "La chasse-galerie" et du "Loup-garou * mettent en scène, successivement, deux processus distincts de victimisation: si, dans la première, la victime appartient à la communauté, dans la deuxième, par contre, elle est extracommunautaire et n'en conforte que davantage l'homogénéité du clan. Un conte de l'abbé Casgrain, "La jongleuse", que Tremblay analyse dans ce même chapitre, avait d'ailleurs déjà opéré ce glissement victimaire vers la figure de l'Indien et celle de la femme néfaste. Le même processus est à l'œuvre dans le premier roman québécois, L'influence d'un litre, dans lequel l'esprit d'aventure, incarné par la quête d'Amand, se trouve "court-circuitée" au profit du maintien de l'ordre social, signifié par le conformisme social de 
Saint-Céran. Les deux contes enchâssés dans la trame du roman, "L'étranger" et "L'homme du Labrador ", illustrent d'ailleurs le triomphe de l'unilinguisme mytho-romanesque, hérité de la tradition orale, sur le récit d'aventures; à cet égard, la mésaventure de Rose Latulipe apparaît symptomatique de la misogynie et de la suprématie du pouvoir patriarcal.

De la même façon, le romanesque sera dévoyé au profit du mythe et du discours ultramontain dans les anciens Canadiens, Angéline de Montbrun et Un bomme et son pécbé, bien que, sous la pression historique, ce phénomène se produise selon de nouvelles modalités. Ainsi, dans le roman de Philippe Aubert de Gaspé, le mécanisme victimaire se trouve transformé, la rivalité raciale étant subsumée par la solidarité de la noblesse, garante d'une "nouvelle hiérarchie colonialiste". Dans Angéline de Montbrun, c'est tout le romantisme psychologique qui est bientôt subordonné au mytho-romanesque traditionnel: la relation incestueuse entre Angéline et son père, qui transgresse l'un des tabous les plus puissants de la communauté, appelle le châtiment. Le mythe est toujours à l'œuvre dans Un bomme et son péché présence des doubles (Séraphin et Alexis) et du processus de victimisation (la mort de Donalda) - mais les premières failles apparaissent à l'intérieur même du discours dominant, qui tendra désormais au multilinguisme et partant, au romanesque: ainsi, pour la première fois, la vision ultramontaine se trouve confrontée au "projet bourgeois moderne", caractérisé par la quête de l'argent et du sexe, qui la mine de l'intérieur. De cette façon, l'ouvrage de Victor-Laurent Tremblay débouche sur une histoire, non pas du roman, mais du proto-roman québécois, devenant du même coup, à mon avis, un jalon essentiel des études québécoises.

Jean Morency 